\title{
Green Approach for the Synthesis of Copper Oxide Nanoparticles and its Antibacterial Effect against Methicillin-resistant Staphylococcus aureus (MRSA)
}

\author{
Shahnaz Majeed ${ }^{1 *}$ (D) Ahmad Najmi Bin Shukhairi ${ }^{1}$ and Mohammed Danish ${ }^{2}$ \\ ${ }^{1}$ Faculty of Pharmacy and Health, Universiti Kuala Lumpur, Royal College of Medicine, Ipoh Perak, 30450, \\ Malaysia. \\ ${ }^{2}$ Bioresource Technology Section, School of Industrial Technology, Universiti Sains Malaysia, 11800 Penang, \\ Malaysia.
}

\begin{abstract}
Nowadays, nanotechnology has gained promising advantages in the medical and pharmaceutical field by improving the delivery of drug to the target site. Morinda citrifolia $\mathrm{L}$. belongs to the genus Morinda of the family Rubiaceae and know as 'Pokok Mengkudu' in Malay. Aqueous extract of Morinda citrifolia treated with copper (II) sulfate results in the formation of copper oxide nanoparticles. The size of synthesized copper oxide nanoparticles (CuONPs) was $10-30 \mathrm{~nm}$ spherical in shape using TEM analysis. UV spectrophotometer showed the absorption peak at $306 \mathrm{~nm}$. SEM analyses confirm the surface morphology of nanoparticles showed spherical shaped particles. FTIR spectroscopy showed broad absorption bands between 2800 and $4000 \mathrm{~cm}^{-1}$ showed $\mathrm{C}-\mathrm{O}, \mathrm{OH}, \mathrm{C}=\mathrm{O}$ stretch are associated with nanoparticles. Zeta potential showed the value of $21.8 \mathrm{mV}$ and $-6.45 \mathrm{mV}$ confirms the stability of nanoparticles. These CuONPs showed good antibacterial activity against Staphylococcus aureus (ATCC 33591) 20mm, Staphylococcus epidermidis (ATCC 35984) $16 \mathrm{~mm}$, Salmonella typhi, 17mm Escherichia coli (ATCC 25922) 18mm and Vibrio cholerae $20 \mathrm{~mm}$. CuONPs also had significant antibacterial properties against Methicillin-resistance Staphylococcus aureus (MRSA) (ATCC 4330). These CuONPs also show good synergistic affect along with Ceftriaxone, Gentamycin and Amoxicillin antibiotic against bacterial pathogens respectively.

Keywords: CuONPs, Morinda citrifolia, TEM analysis, FTIR Spectroscopy, Zeta potential analyser, antibacterial properties
\end{abstract}

*Correspondence: shahnazmajeed5@gmail.com

(Received: October 6, 2021; accepted: December 20, 2021)

Citation: Majeed S, Bin Shukhairi AN, Danish M. Green Approach for the Synthesis of Copper Oxide Nanoparticles and its Antibacterial Effect against Methicillin-resistant Staphylococcus aureus (MRSA). J Pure Appl Microbiol. 2022;16(1):708-716. doi: 10.22207/JPAM.16.1.74

(C) The Author(s) 2022. Open Access. This article is distributed under the terms of the Creative Commons Attribution 4.0 International License which permits unrestricted use, sharing, distribution, and reproduction in any medium, provided you give appropriate credit to the original author(s) and the source, provide a link to the Creative Commons license, and indicate if changes were made. 


\section{INTRODUCTION}

Antibiotics are used to treat bacterial infections. Bacteria can undergo genetic mutation which results in antibiotic resistance. As a self-defense mechanism, this mutation occurs spontaneously in the bacterial chromosome, which reduces or even exterminates the efficacy of antibiotics. ${ }^{1}$ Bacterial resistance was widely spread in the ecosystem, in fact, over 2 million people in the United States eventually be affected yearly by this antibiotic resistance bacteria, and almost 24,000 people died. ${ }^{2}$ Nowadays, it can be overcome by emerging nanotechnology into the biomedicine field to improve drugs capabilities and effectiveness. ${ }^{3}$

Nanotechnology is the study of manipulating matter into the nano-size range between $1 \mathrm{~nm}$ to $100 \mathrm{~nm}$. In the biotechnology field, nanoparticles are very helpful in health science because they can improve drug delivery to the target site. This nanotech can produce effective non-resistance-inducing bactericides with selective toxicity against broad spectrum bacteria in the presence of fibroblast cells. ${ }^{4}$ Mechanisms of action of nanoparticles are currently unknown, but the most approved mechanisms include metal ion release oxidative stress induction and nonoxidative mechanism. ${ }^{5}$

Copper oxide nanoparticles were reported to have antibacterial properties against several types of bacteria, such as E. coli (MTCC 443) and S. aureus (MTCC 737). The size of copper oxide nanoparticles significantly affects the antibacterial properties of the nanoparticles. ${ }^{6}$ The method to synthesize the copper oxide nanoparticles is essential since it may control the morphology and size of the nanoparticles. ${ }^{7}$ Nowadays, green synthesis of copper oxide nanoparticles is very popular, since it is more stable and environmentally friendly, which can avoid the use of a harsh, toxic reducing agent that harmful to health. ${ }^{8}$

Morinda citrifolia L. belongs to the genus Morinda of the family Rubiaceae and know as 'Pokok Mengkudu' in Malay. Morinda citrifolia L. is one of the most popular herbal plants in the Southeast Asia region and can be found in some parts of Australia. This plant is traditionally used by a Polynesian culture to treat fever, body ache, lower blood pressure, antidiabetic effect, constipation, asthma, and many more. ${ }^{9,10}$ Proxeronine is one of the active constituents that can be found in Morinda Citrifolia which is a crucial component to synthesize Xeronine. Xeronine had showed good pharmacological effect, which involves anticancer, anti-inflammatory, and antioxidant. ${ }^{11}$ Other than that, for antibacterial properties, this fruit contains Alizarin, L-asperuloside, and Acubin are very good against various types of bacteria pathogens. ${ }^{12}$

So, this research aims to biosynthesize copper oxide nanoparticles from the aqueous extract of Morinda citrifolia and its antibacterial properties against various bacterial pathogens. This antibacterial property will be compared with different available antibiotics in the market and tested against Methicillin-resistance Staphylococcus aureus were studied.

\section{MATERIALS AND METHODS Collection of plant}

Morinda citrifolia L. belongs to the genus Morinda of the family Rubiaceae and know as 'Pokok Mengkudu' in Malay. The leaves of Morinda citrifolia were collected from Sultan Haji Ahmad Shah Agriculture Park, Kuantan and were authenticated by a botanist. The leaves were dried by the air-dry method. After the drying process, the leaves were grinded into powder form by using a blender.

\section{Extraction of Morinda citrifolia}

10 grams of dried powdered Morinda citrifolia leaves were mixed with $100 \mathrm{~mL}$ of water in a beaker. By using a hot plate, the mixture was heated until $60^{\circ} \mathrm{C}$ for 10 minutes. The mixture was filtered into a conical flask by using filter paper. The filtrate was collected from the conical flask.

\section{Facile synthesis of copper oxide nanoparticles}

$5 \mathrm{mM}$ of copper (II) sulphate $\left(\mathrm{CuSO}_{4}\right)$ was used to synthesize the copper oxide nanoparticles. $80 \mathrm{mg}$ of $\mathrm{CuSO}_{4}$ (Sigma Aldrich USA) was mixed with $90 \mathrm{~mL}$ of water, and $10 \mathrm{~mL}$ Morinda citrifolia extract was added into the solution. The mixture was kept in a conical flask and mouth of conical flask was covered with aluminum foil. It was held for 72 hours on a rotary shaker at 160rpm. The colour of the mixture was changed, which indicates the formation of CuONPs. The solution was poured into a glass petri dish and was dried in the oven at $80^{\circ} \mathrm{C}$ for 24 hours. The dried solution was scrapped into powder form. 


\section{Characterization of copper oxide nanoparticles Fourier Transform Infrared Spectroscopy (FTIR) Analysis}

FTIR (Nicolet FTIR model) analysis is infrared radiation that is passed through and absorbed by the copper oxide nanoparticles. Rotational and/or vibrational energy was obtained from radiation absorption by the CuONPs in a spectral region of $4000 \mathrm{~cm}^{-1}$ to $500 \mathrm{~cm}^{-1}$. This analysis was used to determine the functional groups present in CuONPs.

\section{UV Visible spectroscopy}

Approximately $1 \mathrm{~mL}$ CuONPs solution was poured into a quartz cuvette and put in the spectrophotometer. The ultraviolet absorption has been measured. UV visible spectroscopy (Shimadzu 1800) was confirmed the presence of CuONPs from the range of 300-600nm UV spectrum.

Transmission Electron Microscope and Scanning Electron microscope

For TEM (Zeiss, Libra 120) analysis, the CuONPs solution was sonicated for half an hour in a sonicator before being placed in the microscope. This microscope helps to characterize the size, shape, and electrostatic charge and for SEM (Fei, Model Quanta FEG 650), CuONPs solution was lyophilized, and dried powder form of nanoparticles was subjected for SEM analysis. Zeta Potential analysis

Zeta potential (Malvern, UK) was to determine the stability of CuONPs and its magnitude of electrostatic repulsion between the particles. CuONPs solution was diluted by adding deionized water. The sample was placed into the zeta potential analyzer. The data were evaluated using phase analysis light scattering.

Evaluation of antibacterial activity

Preparation of agar plate

$14 \mathrm{~g}$ of nutrient agar powder was weighed by using a weighing balance. The agar powder was mixed together with $500 \mathrm{~mL}$ water in an autoclave bottle. The mixture was stirred continuously to ensure uniformly mixed. The bottle was sterilized by using an autoclave machine for 20 minutes at $121{ }^{\circ} \mathrm{C}$. The melted agar was poured into sterile Petri dishes after the sterilization process was completed. The Petri dishes were kept horizontally, and the plates were cap with the cover once it had solidified.

\section{Cultivation of bacteria strain}

For the determination of antibacterial activity, there are five types of bacteria used such as Escherichia coli (ATTC-5922), Salmonella typhi (ATC-14028), Staphylococcus aureus (ATTC-3591), Staphylococcus epidermidis (ATTC-35984), Vibrio cholera (ATCC-14033), and Methicillin-resistance Staphylococcus aureus (MRSA) (ATCC- 4330) were obtained from ATCC. These bacteria strains were inoculated in nutrient agar broth and were incubated in the incubator for 2-3 hours. The incubation was completed once the broth became cloudy. The cultured bacteria were swabbed into a petri dish containing nutrient agar.

\section{Antimicrobial activity test}

The powder form of CuONPs was mixed with $1 \mathrm{~mL}$ of water, and the mixture was sonicated for 10 minutes in the sonicator to ensure nanoparticles uniformly dispersed. Each petri dish containing cultured bacteria was introduced with four blank discs and one positive control, which was ofloxacin disc. The blank discs were impregnated with $10 \mu \mathrm{g} / \mathrm{mL}, 20 \mu \mathrm{g} / \mathrm{mL}, 30 \mu \mathrm{g} / \mathrm{mL}$, and $40 \mu \mathrm{g} / \mathrm{mL}$ of CuONPs. The plates were covered and incubated for one day in the incubator at 37 ${ }^{\circ} \mathrm{C}$. Zone of inhibition of the discs was observed and recorded for further comparison and analysis.

\section{Synergistic effect test}

The cultured bacterial strain was swabbed onto prepared nutrient agar plates. Two Ceftriaxone discs, two Gentamycin discs (Nano life quest) and two Amoxicillin discs were used to determine the synergistic effect of the CuONPs. One out of two antibiotic discs was impregnated with $15 \mu \mathrm{g} / \mathrm{mL}$ of CuONPs solution and incubated for 8 hours. After the incubation process, the diameter of the inhibitory zone was measured. The results of the synergistic effect of CuONPs with antibiotics were compared with CuONPs alone.

Antibacterial and synergistic study on Methicillinresistant Staphylococcus aureus (MRSA)

Nutrient agar containing MRSA (ATTC4330) bacteria was introduced with two antibiotic discs and one blank disc. One of the antibiotic discs was impregnated with $20 \mu \mathrm{g} / \mathrm{mL}$ of CuONPs, and the blank disc was impregnated with $40 \mu \mathrm{g} / \mathrm{mL}$ of CuONPs. There were three types of the antibiotic disc such as Vancomycin disc, Ceftriaxone disc, and Gentamycin disc (Nano Life Quest). 


\section{RESULTS AND DISCUSSION}

$10 \mathrm{~mL}$ of extracted Morinda citrifolia solution was added to $90 \mathrm{~mL}$ of $5 \mathrm{mM}$ of copper (II) sulphate solution to produce CuONPs. The solution was placed on a rotary shaker at 150rpm for 3 days to increase the agitation process of nanoparticles in the solution. Colour change of the solution was indicated formation nanoparticles was completed Fig. 1.

Characterization of copper oxide nanoparticles

CuONPs were detected by using UV-Visible spectroscopy. $1 \mathrm{ml}$ of CuONPs solution were diluted by adding $3 \mathrm{ml}$ of distilled water. The solution was poured into a quartz cuvette. The sample was placed under UV-Visible spectrophotometer. Fig. 2 showed the absorption peak at $306 \mathrm{~nm}$, which indicated the presence of CuONPs. ${ }^{13}$ This showed that the copper (II) sulphate had been successfully reduced into the copper oxide nanoparticles.

Table 1. Functional groups/bond involved in CuONPs analysed by FTIR

\begin{tabular}{|c|c|c|}
\hline No. & $\begin{array}{l}\text { Absorption Peak } \\
\left(\mathrm{cm}^{-1}\right) \ln \text { CuONPs }\end{array}$ & $\begin{array}{c}\text { Bond/Functional } \\
\text { Group }\end{array}$ \\
\hline 1 & 3412.73 & $\mathrm{OH}$ stretching vibrations \\
\hline 2 & 2928.79 & $\mathrm{O}=\mathrm{C}=\mathrm{O}$ vibration \\
\hline 3 & 1561.48 & $\mathrm{C}-\mathrm{H}$ \\
\hline 4 & 1410.88 & $\mathrm{C}=\mathrm{O}$ stretching \\
\hline 5 & 1074.78 & $\begin{array}{c}\mathrm{C}-\mathrm{O} \text { stretching in } \\
\text { amino acid }\end{array}$ \\
\hline 6 & 650.36 & Stretching of $\mathrm{CuO}$ \\
\hline
\end{tabular}
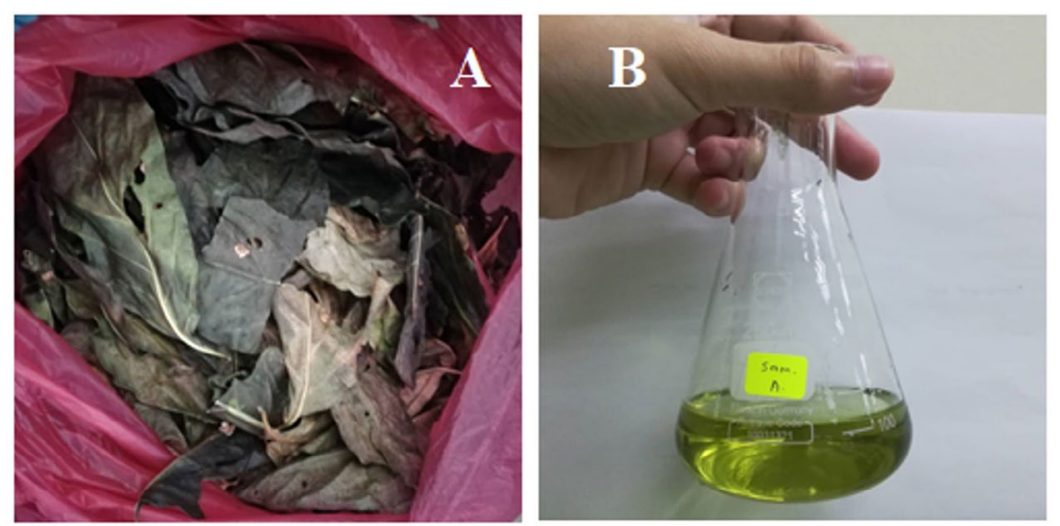

Fig. 1. A- Dried leaves of Morinda citrifolia, B- Synthesized CuONPs.

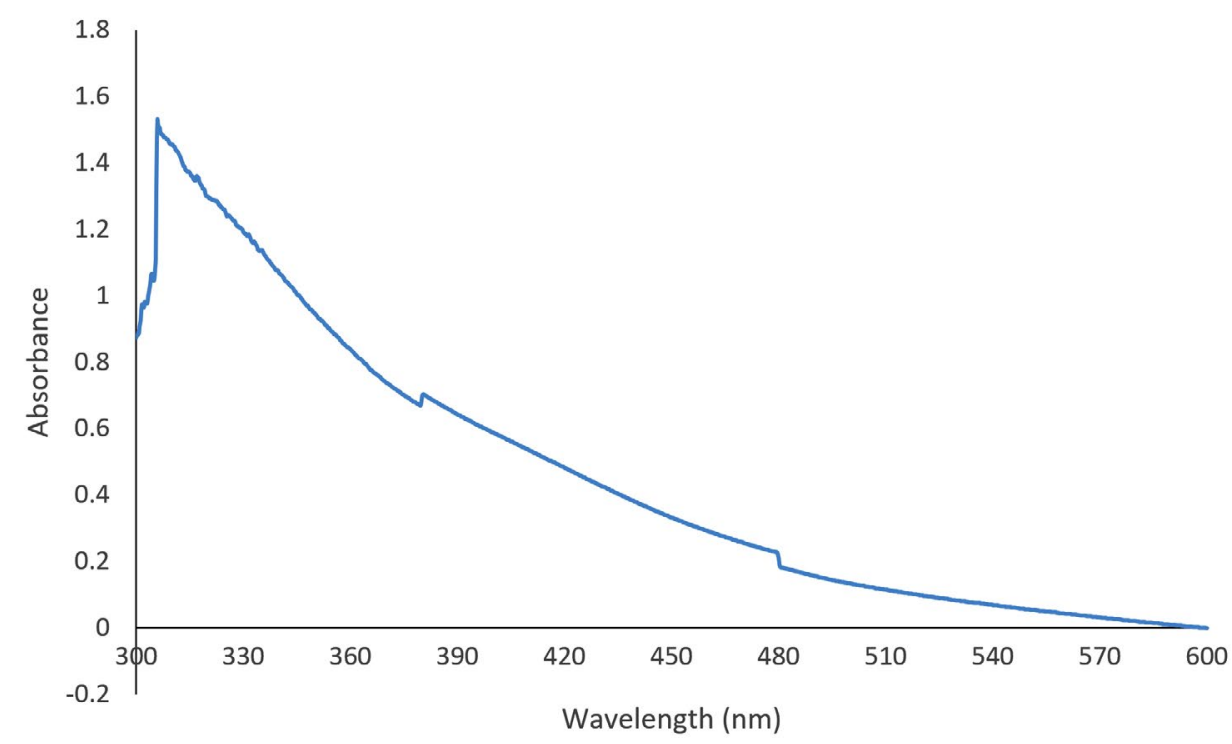

Fig. 2. Graph of UV-Visible of copper oxide nanoparticles. 
Fig. 3 showed the Fourier Transmission Infrared spectra of copper oxide nanoparticles. The spectrum showed broad absorption bands between 500 and $4000 \mathrm{~cm}^{-1}$ in which $\mathrm{OH}$-groups on the surface of the copper oxide nanoparticles. In the range of $500-700 \mathrm{~cm}^{-1}$, there were several infrared absorption peaks that showed the vibrational modes of copper oxide nanoparticles. The prominent peak was observed to be $650 \mathrm{~cm}^{-1}$ which $\mathrm{CuO}$ stretch and the functional group was shown in Table $1 .^{14}$

CuONPs were characterized by using Transmission Electron Microscope. TEM analysis provided details about the particle size, shape. The size of CuONPs will determine the antibacterial effect against bacterial pathogens. Fig. 4 showed that copper oxide nanoparticles formed were spherical in shape and were $10-30 \mathrm{~nm}$ in size, while

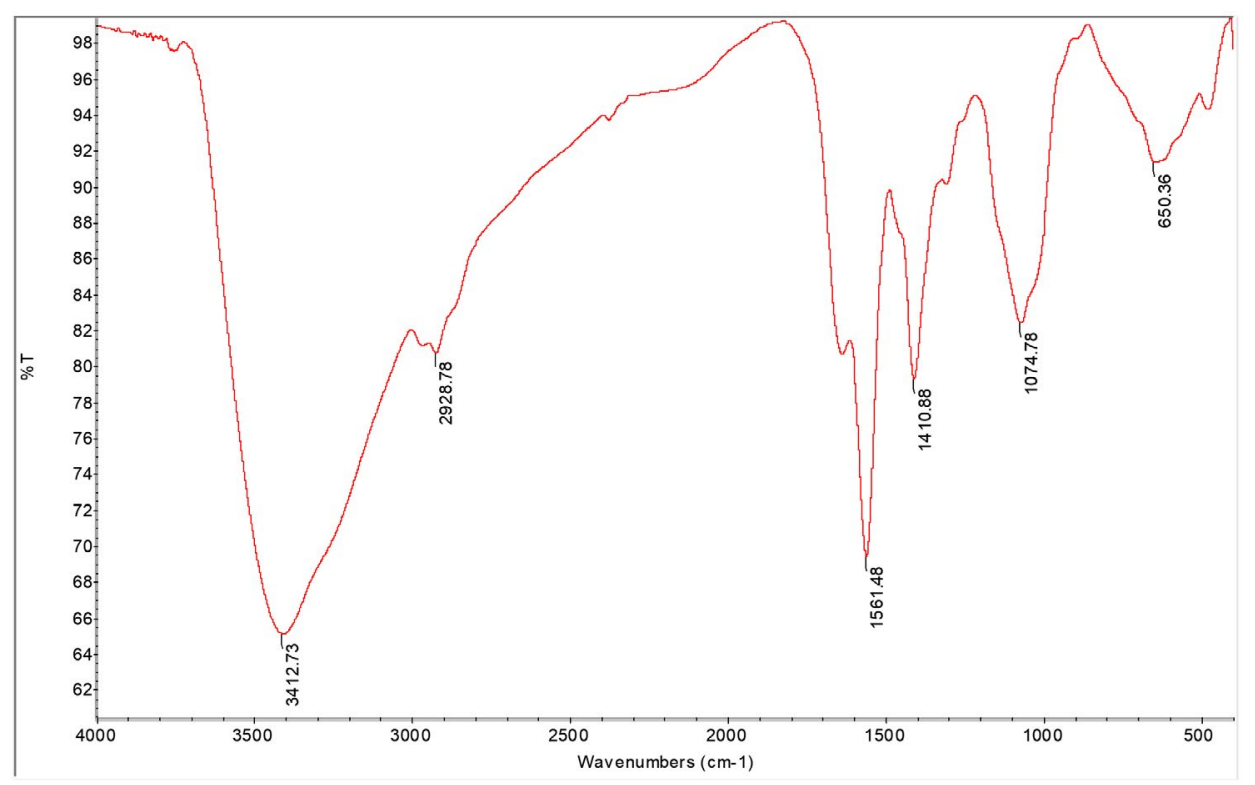

Fig. 3. FTIR analysis of copper oxide nanoparticles.

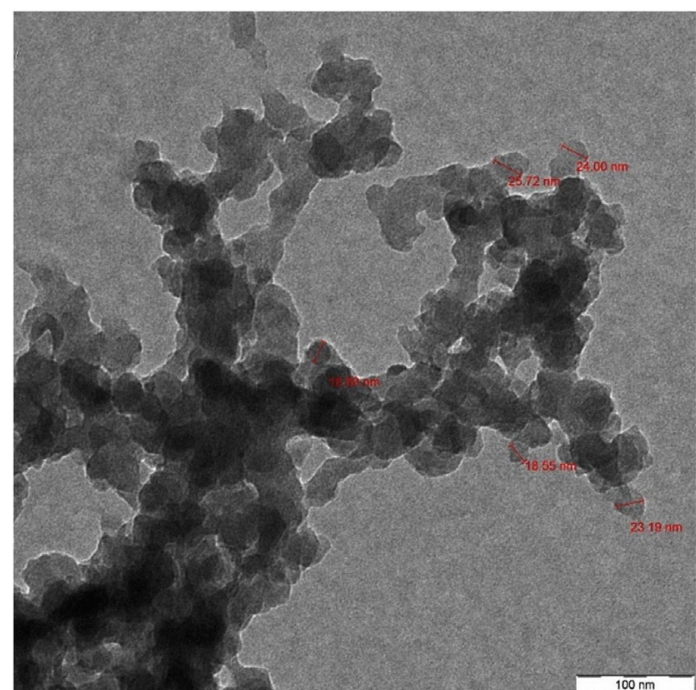

Fig. 4. TEM analysis of copper oxide nanoparticles.
SEM analysis showed particles are agglomerated and evenly distributed Fig. 5 .

Zeta potential analysis was done to determine the stability of CuONPs in water dispersants. CuONPs tend to clump together due attraction of Van der Waals forces. The aggregation due to this Van der Waals forces may be overcome by electrostatic repulsion. Zeta potential was to measure the charge on the surface of CuONPs. Fig. 6 showed that the zeta potential of CuONPs were at $21.8 \mathrm{mV},-6.45 \mathrm{mV}$ in water dispersion confirms the stability of nanoparticles. The two values showed that the particles are agglomerated and there is little bit electrostatic attraction between the particles.

\section{Evaluation of antibacterial activity}

Disc diffusion method was used to test the antibacterial properties of the copper oxide 
nanoparticles tested against several bacteria such as Staphylococcus aureus, Staphylococcus epidermidis, Escherichia coli, Salmonella typhi and Vibrio cholera were brought ATCC. Each plate was swabbed with one type of bacteria. The plated was inserted with four blank discs. The blank discs were impregnated with $10 \mu \mathrm{g}, 20 \mu \mathrm{g}, 30 \mu \mathrm{g}$ and $40 \mu \mathrm{g}$ of copper oxide nanoparticle. The plates

Table 2. Zone of inhibition of bacteria against copper oxide nanoparticles (Experiment repeated thrice and average value was calculated)

\begin{tabular}{|c|c|c|c|c|c|}
\hline \multirow[t]{2}{*}{$\begin{array}{l}\text { Bacteria } \\
\text { pathogens }\end{array}$} & \multicolumn{4}{|c|}{$\begin{array}{l}\text { Copper oxide nanoparticles } \\
\text { Zone of inhibition in } \mathrm{mm}\end{array}$} & \multirow[t]{2}{*}{$\begin{array}{c}\text { Positive control } \\
\text { Ofloxacin disc }\end{array}$} \\
\hline & $10 \mu \mathrm{g}$ & $20 \mu \mathrm{g}$ & $30 \mu \mathrm{g}$ & $40 \mu \mathrm{g}$ & \\
\hline E. coli & $9 \pm 0.33$ & $14 \pm 0.21$ & $16 \pm 68$ & $18 \pm 0.54$ & $32 \pm 0.09$ \\
\hline S. typhi & $10 \pm 0.11$ & $12 \pm 0.33$ & $15 \pm 0.98$ & $17 \pm 1.09$ & $39 \pm 0.33$ \\
\hline S. aureus & $10 \pm 0.13$ & $14 \pm 0$ & $18 \pm 0.23$ & $20 \pm 0.39$ & $33 \pm 0.45$ \\
\hline S. epidermidis & $9 \pm 0.83$ & $13 \pm 43$ & $15 \pm 0.54$ & $16 \pm 0.44$ & $39 \pm 0.87$ \\
\hline V. cholera & $10 \pm 0.33$ & $14 \pm 0.04$ & $18 \pm 0.33$ & $20 \pm 0.32$ & $43 \pm 0.26$ \\
\hline
\end{tabular}

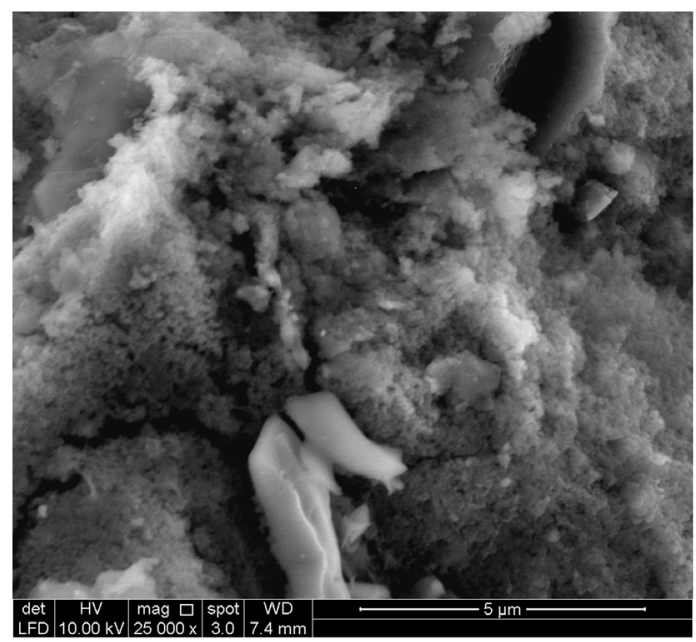

Fig. 5. SEM analysis of CuONPs. were incubated in the incubator at $37^{\circ} \mathrm{C}$ for 8 hours. ${ }^{15-17}$ The diameter of the zone of inhibition was measured after the incubation. The results were recorded for further analysis Table 2 and Fig. 7.

A synergistic study was carried out by using three antibiotic discs such as Gentamycin disc, Ceftriaxone disc, and Amoxicillin disc. Each plate contains two discs of those antibiotics. One of the antibiotic discs was impregnated with $15 \mu \mathrm{g}$ of CuONPs. So, another antibiotic disc was kept as a positive control. The plates were incubated in the incubator at $37^{\circ} \mathrm{C}$ for 8 hours. ${ }^{18}$ The diameter of the zone of inhibition was measured after the incubation. The results were recorded and shown in Table 3 and Fig. 8.

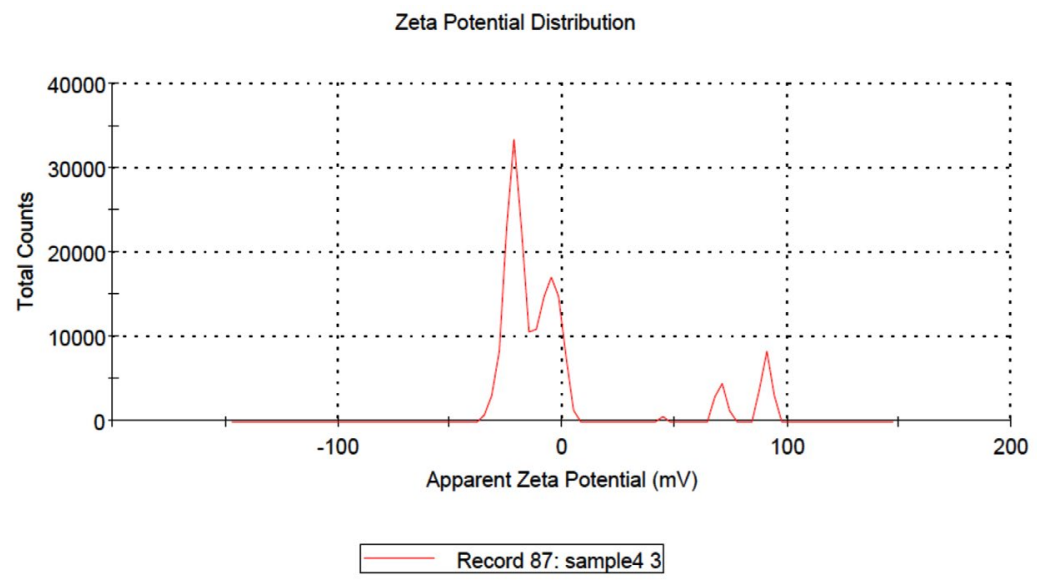

Fig. 6. Zeta potential analysis of copper oxide nanoparticles. 
Copper oxide nanoparticles also were tested against antibiotic resistance bacteria Methicillin-resistance Staphylococcus aureus (MRSA). The bacteria were cultured into the nutrient broth and was swabbed on three Petri dishes. Two antibiotic discs for each type of antibiotic were used to test the synergistic effect of the CuONPs. The antibiotic discs that had been used were Gentamycin disc, Amoxicillin disc, and Ceftriaxone discs. One out of two-disc was impregnated with $20 \mu \mathrm{g}$ of copper oxide nanoparticles, and another antibiotic disc was kept as a positive control. One blank disc was used to test antibacterial activities against MRSA and was impregnated with $40 \mu \mathrm{g}$. All the plates were incubated in an incubator at $37^{\circ} \mathrm{C}$ for 8 hours. Zone of inhibition had been measured after the incubation, and results were shown in
Table 4 and Fig. 9. These biologically synthesized CuONPs showed excellent antibacterial effects as well as synergism. These cups also showed a good antibacterial effect against drug-resistant MRSA.

There are various reports available that are widely accepted that showed the mechanism of metallic nanoparticles. ${ }^{19}$ The nanoparticles enter the cells through the cell membrane, thereby causing oxidative distress by producing reactive oxygen species and lipid peroxidation. Also, these ROS enters the DNA, damages it, and cause the death of pathogen. ${ }^{22,23}$ Yanfeng et al. reported that $\mathrm{Ag} / \mathrm{Au}$ possess good antibacterial activity against various bacterial pathogens. ${ }^{24}$ Another study showed that magnetite nanoparticles also possess good antibacterial activity against various bacterial pathogens.

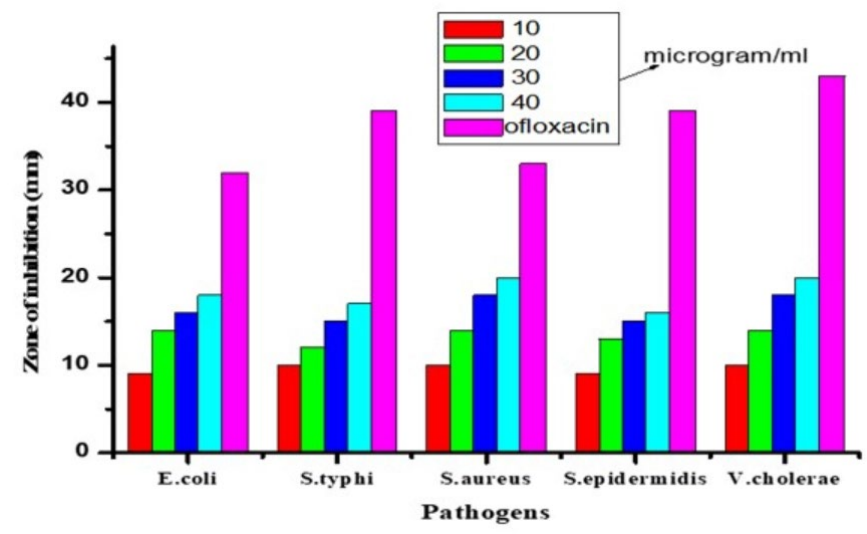

Fig. 7. Antibacterial activity of CuONPs against several bacteria at different concentration. (ST) Salmonella typhi (SE) Staphylococcus epidermidis (VC) Vibrio cholerae (EC) Escherichia coli (SA) Staphylococcus aureus (1) $10 \mu \mathrm{g}$ of

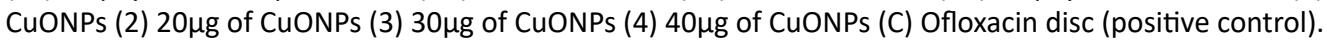

\section{Synergistic effect}

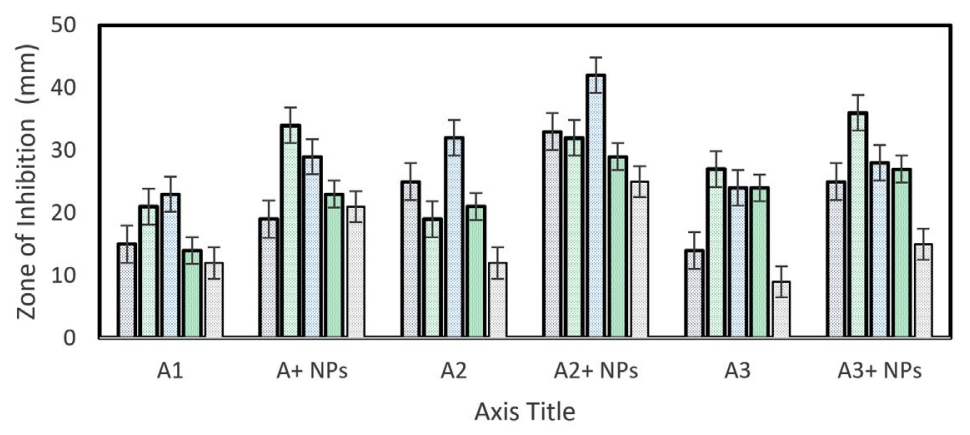

$\boldsymbol{\square E}$. coli $\square$ S. typhi $\boldsymbol{\nabla V}$. cholera $\square$ S. epidermidis $\square$ S. aureus

Fig. 8. Synergistic effect of several antibiotics with CuONPs on several types of bacteria. (ST) Salmonella thyphi (SE) Staphylococcus epidermidis (VC) Vibrio cholerae (EC) Escherichia coli (SA) Staphylococcus aureus (1) positive control

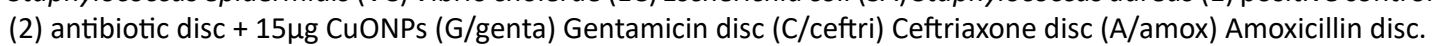


Table 3. Synergistic effect of several antibiotics with CuONPs on pathogenic bacteria. Zone of inhibition was measured in millimeter $(\mathrm{mm})$

\begin{tabular}{|c|c|c|c|c|c|c|}
\hline \multirow[t]{2}{*}{ Bacterial } & \multicolumn{2}{|c|}{ Gentamycin disc(A1) } & \multicolumn{2}{|c|}{ Ceftriaxone $\operatorname{disc}(\mathrm{A} 2)$} & \multicolumn{2}{|c|}{ Amoxicillin disc(A3) } \\
\hline & $\mathrm{A} 1$ & $\begin{array}{c}\mathrm{A} 1+15 \mu \mathrm{g} / \\
\text { disc NPs }\end{array}$ & $\mathrm{A} 2$ & $\begin{array}{l}\text { A2+15 } \mu \mathrm{g} / \\
\text { disc NPs }\end{array}$ & A3 & $\begin{array}{c}A 3+15 \mu g \\
\text { NPs }\end{array}$ \\
\hline E. coli & $15 \pm 0.17$ & $19 \pm 0.43$ & $25 \pm 0.09$ & $33 \pm 0.22$ & $14 \pm 0.75$ & $25 \pm 0.43$ \\
\hline S. Typhi & $21 \pm 0.43$ & $34 \pm 0.22$ & $19 \pm 1.33$ & $32 \pm 0.98$ & $27 \pm 0.83$ & $36 \pm 0.72$ \\
\hline V. cholera & $23 \pm 1.10$ & $29 \pm 0.82$ & $32 \pm 0.55$ & $42 \pm 0.03$ & $24 \pm 0.26$ & $28 \pm 0.21$ \\
\hline S. epidermidis & $14 \pm 0.64$ & $23 \pm 0.97$ & $21 \pm 0.14$ & $29 \pm 0.83$ & $24 \pm 0.88$ & $27 \pm 0.43$ \\
\hline S. aureus & $12 \pm 0.34$ & $21 \pm 0.12$ & $12 \pm 0.39$ & $25 \pm 0.43$ & $9 \pm 0.15$ & $15 \pm 0.13$ \\
\hline
\end{tabular}

Table 4. Zone of inhibition and synergistic study on Methicillin-resistance Staphylococcus aureus

\begin{tabular}{|c|c|c|c|c|c|c|c|}
\hline \multirow[t]{2}{*}{ Bacteria } & \multicolumn{2}{|c|}{ Vancomycin(A1) } & \multicolumn{2}{|c|}{ Ceftriaxone(A2) } & \multicolumn{2}{|c|}{ Gentamicin (A3) } & \multirow{2}{*}{$\begin{array}{l}\text { CuONPs } \\
40 \mu \mathrm{g} / \text { disc }\end{array}$} \\
\hline & $\mathrm{A} 1$ & $\begin{array}{c}\mathrm{A} 1+20 \mu \mathrm{g} / \\
\text { disc NPs }\end{array}$ & $\mathrm{A} 2$ & $\begin{array}{c}\mathrm{A} 2+20 \mu \mathrm{g} / \\
\text { disc NPs }\end{array}$ & A3 & $\begin{array}{c}\mathrm{A} 3+20 \mu \mathrm{g} / \\
\text { disc NPs }\end{array}$ & \\
\hline MRSA & $22 \pm 0.55$ & $33 \pm 0.32$ & $33 \pm 0.12$ & $38 \pm 0.92$ & $31 \pm 0.39$ & $36 \pm 0.09$ & $18 \pm 0.34$ \\
\hline
\end{tabular}

\section{MRSA}

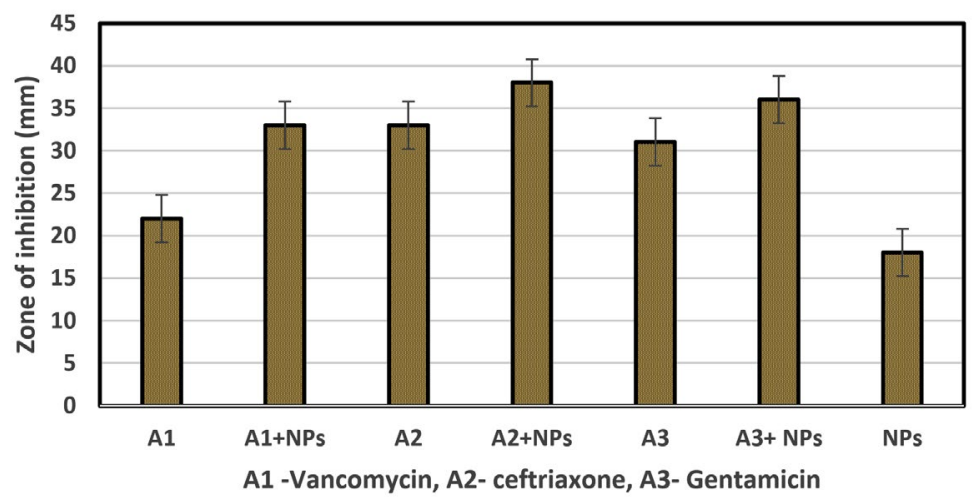

Fig. 9. Zone of inhibition and synergistic study on Methicillin-resistance Staphylococcus aureus.

\section{CONCLUSION}

The above results showed that the CuONPs were successfully synthesized from the extract of Morinda citrifolia leaves. CuONPs exhibit good antibacterial activity against various bacterial pathogens such as Escherichia coli, Staphylococcus aureus, Staphylococcus epidermidis, Salmonella typhi, and Vibrio cholera. Copper oxide nanoparticles also showed a good synergistic effect against selected antibiotics such as Amoxicillin, Ceftriaxone and Gentamycin on selected pathogens. CuONPs showed excellent antibacterial effect against Methicillin-resistance Staphylococcus aureus (MRSA) and showed good synergistic effect against Ceftriaxone, Gentamycin, and vancomycin antibiotics.

\section{ACKNOWLEDGMENTS}

The authors would like to thank University Kuala Lumpur Royal College of Medicine and Universiti Sains Malaysia for providing the necessary facilities to carry out this study.

\section{CONFLICT OF INTEREST}

The authors declare that there is no conflict of interest.

\section{AUTHORS' CONTRIBUTION}

$S M$ and ANBS designed the experiments and prepared the manuscript. ANBS and MD performed the experiments. SM supervised and reviewed the manuscript. All authors read and approved the final manuscript for publication. 


\section{FUNDING}

None.

\section{DATA AVAILABILITY}

The data presented in this manuscript will be available upon request from corresponding author

\section{ETHICS STATEMENT}

Not applicable.

\section{REFERENCES}

1. Gupta PD, Birdi TJ. Development of botanicals to combat antibiotic resistance. J Ayurveda Integr Med. 2017;8(4):266-275. doi: 10.1016/j.jaim.2017.05.004

2. Antibiotic/Antimicrobial Resistance-CDC. Centers for Disease Control and Prevention. 2017. https://www. cdc.gov/drugresistance/biggest-threats.html

3. Suri SS, Fenniri H, Singh B. Nanotechnology-based drug delivery systems. J Occup Med Toxicol. 2007;2:16. doi: 10.1186/1745-6673-2-16

4. Ghanbar S, Fumakia M, Ho EA, Liu S. A new strategy for battling bacterial resistance: Turning potent, non-selective and potentially non-resistanceinducing biocides into selective ones. Nanomedicine: Nanotechnol Biol Med. 2018;14(2):471-481. doi: 10.1016/j.nano.2017.11.014

5. Wang L, Hu C, Shao L. The antimicrobial activity of nanoparticles: present situation and prospects for the future. Int J Nanomedicine. 2017;12:1227-1249. doi: 10.2147/IJN.S121956

6. Ananth A, Dharaneedharan S, Heo M-S, Moka YS. Copper oxide nanomaterials: Synthesis, characterization and structure-specific antibacterial performance. Chem Eng J. 2015;262:179-188. doi: 10.1016/j.cej.2014.09.083

7. Xu J, Ji W, Shen Z, et al. Preparation and characterization of CuO nanocrystals. J Solid State Chem. 1999;147(2):516-519. doi: 10.1006/jssc.1999.8409

8. Irvani S. Green synthesis of metal nanoparticles using plants. Green Chemistry. 2011;13:2638-2650. doi: 10.1039/c1gc15386b

9. Nelson. Species Profiles for Pacific Island Agroforestry: Morinda Citrifolia (noni). Traditional Tree Initiative. 2006. https://guides.library.manoa.hawaii.edu/ paccrops/no

10. Wang MY, West BJ, Jensen CJ, et al. Morinda citrifolia (Noni): a literature review and recent advances in Noni research. Acta pharmacologica Sinica. 2002;23(12):1127-1141.

11. Heinicke RM. The Pharmacological Active Ingredients of Noni. Pacific Tropical Botanical Garden. 1985;15:1014.

12. Levand $\mathrm{O}$, Larson $\mathrm{OH}$. Some chemical constituents of Morinda. Planta Med. 1979;36(6):186-187. doi: 10.1055/s-0028-1097264

13. Lee HY, Song JY, Kim BS. Biological synthesis of copper nanoparticles using Magnolia Kobus leaf extract and their antibacterial activity. J Chem Technol Biotechnol.
2013;88(11):1971-1977. doi: 10.1002/jctb.4052

14. Vellora V, Padil T, Cernik M. Green synthesis of copper oxide nanoparticles using gum karaya as a biotemplate and their antibacterial application. Int J Nanomedicine. 2013;8:889-898. doi: 10.2147/IJN.S40599

15. Abboud Y, Saffaj T, Chagraoui A, et al. Biosynthesis, characterization and antimicrobial activity of copper oxide nanoparticles (CONPs) produced using brown alga extract (Bifurcaria bifurcata). Applied Nanoscience. 2014;4(5):571-576. doi: 10.1007/s13204-013-0233-x

16. Sathishkumar G, Gobinath C, Karpagam K, Hemamalini V, Premkumar K, Sivaramakrishnan S. Phyto-synthesis of silver nanoscale particles using Morinda citrifolia $\mathrm{L}$. and its inhibitory activity against human pathogens. Colloids Surf B Biointerfaces. 2012;95:235-240. doi: 10.1016/j.colsurfb.2012.03.001

17. Natheer SE, Sekar C, Amutharaj P, Rahman MSA, Khan KF. Evaluation of antibacterial activity of Morinda citrifolia, Vitex trifolia and Chromolaena odorata. Afr J Pharm Pharmacol. 2012;6(11):783-788. doi: 10.5897/ AJPP11.435

18. Sivarajab R, Rahman PKSM, Rajiv P, Narendhran S, Venckatesh R. Biosynthesis and characterization of Acalypha indica mediated copper oxide nanoparticles and evaluation of its antimicrobial and anticancer activity. Spectrochimica Acta Part A: Molecular and Biomolecular Spectroscopy. 2014;129:255-258. doi: 10.1016/j.saa.2014.03.027

19. Eric F, Cakir-Koc R, Yontem M, Torlak E. Synthesis of biologically active copper oxide nanoparticles as promising novel antibacterial-antibiofilm agents. Prep Biochem Biotechnol. 2020;50(6):538-548, doi: 10.1080/10826068.2019.1711393

20. Ali JS, Mannan A, Nasrullah M, Ishtiaq H, Naz S, Zia M. Antimicrobial, antioxidative, and cytotoxic properties of Monotheca buxifolia assisted synthesized metal and metal oxide nanoparticles. Inorganic and Nano-Metal Chemistry. 2020;50(9):770-782, doi: 10.1080/24701556.2020.1724150

21. Gour A, Jain NK. Advances in green synthesis of nanoparticles. Artif Cells Nanomed Biotechnol. 2019;47(1):844-851. doi: 10.1080/21691401.2019.1577878

22. Von Moos N, Slaveykova VI. Oxidative stressinduced by inorganic nanoparticles in bacteria and aquatic microalgae-state of the art and knowledge gaps. Nanotoxicology. 2014;8(6):605-630. doi: 10.3109/17435390.2013.809810

23. Yang Y, Ashraf MA, Fakhri A, Gupta VK, ZhangD. Facile synthesis of gold-silver/copper sulfide nanoparticles for the selective/sensitive detection of chromium, photochemical and bactericidal application. Spectrochimica Acta Part A: Molecular and Biomolecular Spectroscopy. 2021;249:119324. doi: 10.1016/j.saa.2020.119324

24. Inbaraj BS, Kao TH, Sai TY, Chiu CP, Kumar R, Chen $\mathrm{BH}$. The synthesis and characterization of poly $(\nu-$ glutamic acid)-coated magnetite nanoparticles and their effects on antibacterial activity and cytotoxicity. Nanotechnology. 2011;22(7):075101. doi: 10.1088/0957-4484/22/7/075101 